\title{
Early-warning Analysis for Carrying Capacity in Nandaihe International Amusement Centre Based on Fuzzy Inference and Gray Forecasting
}

\author{
Xiuping Yang \\ Lanzhou University of Technology \\ College of Economy and Management \\ Lanzhou, China, \\ yangxp789@163.com
}

\author{
Erchao Li \\ Lanzhou University of Technology \\ College of Electrical and Information Engineering \\ Lanzhou, China \\ lecyxp@lut.cn
}

\begin{abstract}
Nandaihe international amusement centre spot as an example is analyzed in this paper. The paper presents a method based on fuzzy inference and gray forecasting, indexes of tourism environment carrying capacity in scenic spots is established, extract fuzzy rules based on historical data, simulate the situation of tourism environment carrying capacity based on fuzzy inference, gray forecasting model is built for single feature index respectively, and various models are combined in system state formula to forecast, then the forecasting result is used to early-warning with the fuzzy inference model. At last, the method designed is effective.
\end{abstract}

Keywords-Fuzzy Inference; Gray Forecasting; Earlywarning Model; Carrying Capacity

\section{INTRODUCTION}

The tourism environment is the basic conditions for tourism survival and sustainable development. With the development of China's tourism industry, tourism demand rapid expansion, but most of the tourism attractions in the original base is relatively weak, tourist holiday travel is relatively concentrated, and the uneven spatial distribution, resulting in problems of supply and demand, tourism activities on the negative impact of the environment has become increasingly prominent. To achieve the sustainable development of tourism attractions, domestic and foreign scholars in recent years have some research in the early warning of tourist attractions, provide the basis of scientific decision-making for the scenic managers [1]. There are lots of empirical knowledge in the warning theory of tourism field, there are some differences in different types of early warning indicators, and tourism activities is seasonal and random fluctuations, how to select scientific and reasonable indicators and to minimize the influence of human factors in early warning analysis is one of the urgent problem in tourism environment early warning research.

To make the right warning of tourism environment carrying capacity is difficult, because the scenic operating data is lacked and incomplete, which mostly non-linear relationship of the historical data is difficult to predict. On the other hand, the alarm threshold is difficult to determine, since academia is not a unified standard. The system based on gray system theory is studied which the partial information is known. Continuous gray differential function is used for gray prediction model by anglicizing and making predictions for development and changes of the system.
The early-warning model of tourism environment carrying capacity has a high complexity and nonlinearity, while the previous model in traditional sense paid more attention to the linear research and existed large errors. How to research the nonlinear in early-warning systems of the tourism environment carrying capacity and how to apply expert knowledge to the study of the early-warning systems of tourism environment carrying capacity need to solve urgently. At present, for highly complex nonlinear system of tourism environment carrying capacity, intelligent algorithm can simplify the model and obtain good optimization results. In reference [2], BP neural network is a good attempt on early-warning systems of sustainable tourism development. Fuzzy inference system adapts to the nonlinear system that doesn't get an accuracy mathematical model and has uncertain factor. In this paper, the fuzzy inference is introduced into the process of the tourism environment carrying capacity to deal with nonlinearity and uncertainty, indexes of early-warning system of carrying capacity in scenic spots is established, extract fuzzy rules based on historical data, gray forecasting model is built for single feature index respectively, and various models are combined in system state formula to forecast, then the forecasting result is used to early-warning with the fuzzy inference model. At last, an example proves that the early-warning model designed is effective [3].

Nandaihe Resort is located in south-east of Qinhuangdao City, Hebei Province, paralleling with the famous summer resort--Beidaihe, a bridge connected with a coastline of 17.5 kilometers, the total area is 20 square kilometers. Since the Nandaihe international entertainment center is opened up, caused a "Nandaihe Tourism boom" quickly. Economic benefits are from 53 million yuan in 2006, rising to $\$ 1.15$ billion yuan in 2011. Tourist quantity was 110.81 million in 2005 , increasing to 240.68 million in 2011 . Especially since 2008 , the lack of coordination of the tourism environment carrying capacity and tourist quantity gradually revealed. Qinhuangdao is a temperate monsoon climate; the number of tourists is increased significantly in May to October. The tourist quantity comes to the peak in July and August and most of the city tourism spots are resulted in different levels of load carrying which is disadvantage to the sustainable tourist areas. In this paper, the fuzzy inference is introduced into the process of TECC to deal with nonlinearity and uncertainty, indexes of early-warning system of carrying capacity in scenic spots is established, extract fuzzy rules 
based on historical data, gray forecasting model is built for single feature index respectively, and various models are combined in system state formula to forecast, then the forecasting result is used to early-warning with the fuzzy inference model. An example proves that the model designed is effective.

\section{INDEX ABOUT TECC OF NANDAIHE INTERNATIONAL AMUSEMENT CENTRE}

Due to the complexity of the tourism environment system, which involves many factors, the experts of domestic and foreign do not form a single authoritative definition to the tourism environment carrying capacity.

Firstly, based on system analysis and reasonable comprehensive of the selected factors that affect the TECC, this paper uses method of experts investigate and selects warning indicators and important limiting factor of TECC. Secondly, this paper combines with the opinions of experts, visits and monitors the related early-warning indicators. Finally, removes some relatively small impact factors in traditional TECC index, and complements the index appropriately, respectively include the natural environment carrying capacity (F1), economic environment carrying capacity (F2) and social environment carrying capacity (F3), where $\mathrm{x} 1, \mathrm{x} 2, \cdots \cdots, \mathrm{x} 13$ is corresponding base indicators $[1,2]$, and this paper establishes the early-warning indicator system, shown in Table 1.

TABLE I. INDEX OF THE TOURISM ENVIRONMENT CARRYING CAPACITY

\begin{tabular}{|c|c|c|}
\hline \multirow{2}{*}{ F1 } & \multicolumn{2}{|c|}{$x_{1}$ : ecological environment carrying capacity } \\
\hline & \multicolumn{2}{|c|}{$x_{2}$ : tourism resources space carrying capacity } \\
\hline \multirow{8}{*}{ F2 } & \multirow{4}{*}{$\begin{array}{l}\text { F21: Infrastructure } \\
\text { carrying } \\
\text { capacity }\end{array}$} & $x_{3}:$ water facilities carrying capacity \\
\hline & & $x_{4}$ : power facilities carrying capacity \\
\hline & & $x_{5}:$ communication carrying capacity \\
\hline & & $x_{6}:$ transport carrying capacity \\
\hline & \multirow{4}{*}{$\begin{array}{c}\text { F22: tourism } \\
\text { service facilities } \\
\text { carrying capacity }\end{array}$} & $x_{7}:$ accommodation carrying capacity \\
\hline & & $x_{8}$ : dining facilities carrying capacity \\
\hline & & $x_{9}$ : recreational carrying capacity \\
\hline & & $x_{10}$ : shopping facilities carrying capacity \\
\hline \multirow{3}{*}{ F3 } & \multicolumn{2}{|c|}{$x_{11}$ : carrying capacity of the management level } \\
\hline & \multicolumn{2}{|c|}{$x_{12}:$ capacity of local residents mental endurance situation } \\
\hline & \multicolumn{2}{|c|}{$x_{13}$ : tourism aesthetic perception carrying capacity } \\
\hline
\end{tabular}

In this paper, the fuzzy reasoning method is adopted for TECC which is the Nandaihe international amuse center in 2012 July, their specific input data collected are based on the Survey Method. Tourism environment carrying rate (TECR) that reflects the using of TECC is defined the relationship of tourist quantity (TQ) and TECC.

$$
T E C R=T Q / T E C C
$$

According to the different levels of TECR, set the warning interval $\mathrm{Y}_{\mathrm{i}}$, When TECR is in "Weak-load conditions", shows the situation where environment has been protected, but the economic benefits of tourism has not been fully exploited; When the utilization degree of the TECR is in the range of $\left[\mathrm{y}_{\mathrm{a}}, \mathrm{y}_{\mathrm{b}}\right)$, shows that the economic benefits are guaranteed on the basis of the protection of the environment; When the utilization degree of the tourism environment is in the $\left[\mathrm{y}_{\mathrm{b}}, \mathrm{y}_{\mathrm{c}}\right)$ interval, shows that tourism environment is damaged in different degrees; If the utilization degree of the tourism environment is in the interval $\left[\mathrm{y}_{\mathrm{c}}, 1\right]$, shows that the tourism environment is highly overloaded, as shown in Table 2.

TABLE II. WARNING SIgNAL TABLE

\begin{tabular}{|c|c|c|c|c|}
\hline$\left(Y_{i}\right)$ & {$\left[0, y_{a}\right)$} & {$\left[y_{a}, y_{b}\right)$} & {$\left[y_{b}, y_{c}\right)$} & {$\left[y_{c}, 1\right]$} \\
\hline $\begin{array}{c}\text { Utilization } \\
\text { state }\end{array}$ & Weak & Normal & Low & High \\
\hline alarm level & First & None & Second & Third \\
\hline
\end{tabular}

Established a system of early-warning indicators, based on these indicators can generate fuzzy rules for fuzzy inference, there are two ways, first using expert knowledge to generate fuzzy inference rules, the second using various indicators of historical data to generate a fuzzy inference rules. The fuzzy inference rules generated by the expert knowledge have human factors, in this paper, the second way is adopted.

\section{GENERATION OF FUZZY INFERENCE RULES}

Using fuzzy inference rules, assuming $\left\{\mathrm{U}_{1}, \mathrm{U}_{2}, \cdots \cdots, \mathrm{U}_{13}\right\}$ is the range for the basic indicators $\left\{\mathrm{x}_{1}, \mathrm{x}_{2}, \cdots \cdots, \mathrm{x}_{13}\right\}$ in the system of early-warning indicators, where $U_{i}=\left[x_{i}^{-}, x_{i}^{+}\right]$, $i=1,2, \cdots, 13, \mathrm{Y}$ is the early-warning target variable, its domain is $[0,1]$.The general form of fuzzy inference rules is:

If $\mathrm{x}_{1}$ is $\mathrm{A}_{1}$ and $\mathrm{x}_{2}$ is $\mathrm{A}_{2} \cdots \cdots$ and $\mathrm{x}_{13}$ is $\mathrm{A}_{13}$ then $\mathrm{y}$ is $\mathrm{B}$, where $A_{i} \in U_{i}, B \in[0,1]$

$$
\left(x_{1}^{1}, x_{2}^{1}, \cdots, x_{13}^{1} ; y_{1}\right),\left(x_{1}^{2}, x_{2}^{2}, \cdots, x_{13}^{2} ; y_{2}\right), \ldots . .
$$$$
\left(x_{1}^{m}, x_{2}^{m}, \cdots, x_{13}^{m} ; y_{m}\right) \text {, the learning steps is as follows: }
$$

Firstly, each interval corresponds to a fuzzy set $A_{i}^{j}\left(j=1,2, \cdots, N_{i}\right)$, can be membership functions of arbitrary shape. In order to calculate simple, membership function is taken as the triangle. Similarly, the four fuzzy sets are defined in $[0,1]$, the membership function is still taken as a triangle.

Secondly, for the p-th input and output data $\left(x_{1}^{p}, x_{2}^{p}, \cdots, x_{13}^{p} ; y_{p}\right)$, calculated on a different interval $x_{1}^{p}, x_{2}^{p}, \cdots, x_{13}^{p}$ and $y_{p}$ corresponds to the degree of membership, data $x_{1}^{p}, x_{2}^{p}, \cdots, x_{13}^{p}$ and $y_{p}$ are located in the maximum degree of the corresponding interval. $m$ inputoutput pairs can produce $m$ fuzzy rules. 
Thirdly, determine the strength of the fuzzy rules. Because the number of input and output data are usually a lot, and each data produce a rule. Rules are likely to generate conflict. To avoid conflicts, give the strength for each rule, make only one rule with the greatest strength in a conflict group. This will not only resolve the conflict, and the number of rules is greatly reduced. The definition of rule strength is seen in [4].

At last, the rules are generated which does not conflict with other rules, and the rules of conflict groups with the greatest strength.Using the singleton fuzzifier, the product inference engine and the center-average defuzzifier based on the fuzzy rule base created, expressed as follows:

$$
y=f(x)=\frac{\sum_{l=1}^{M} \bar{y}^{l}\left(\prod_{i=1}^{13} \mu_{A_{i}}^{l}\left(x_{i}\right)\right)}{\sum_{l=1}^{M}\left(\prod_{i=1}^{13} \mu_{A_{i}}^{l}\left(x_{i}\right)\right)}
$$

Where $\bar{y}^{l}$ is the center of the fuzzy set B, M is the number of fuzzy rules in the rule base, $\mathrm{x}=(\mathrm{x} 1, \mathrm{x} 2, \cdots \cdots, \mathrm{x} 13)$. Base indicators $\{\mathrm{x} 1, \mathrm{x} 2, \cdots \cdots, \mathrm{x} 13\}$ in the early warning system is denoted by $x_{n}(t)$,where $n \in[1,13]$, $\mathrm{t}$ denotes the time, so select the value of the $\mathrm{k}$-based indicators can constitute the $n \times k$ dimension feature state space[5].

$$
\left[\begin{array}{cccc}
x_{1}(1) & x_{1}(2) & \cdots & x_{1}(k) \\
x_{2}(1) & x_{2}(2) & \cdots & x_{2}(k) \\
\vdots & \vdots & \vdots & \vdots \\
x_{n}(1) & x_{n}(2) & \cdots & x_{n}(k)
\end{array}\right]
$$

Gray prediction model GM $(1,1)$ is used for a single time series prediction which can not reflect the variable interaction, the gray $\operatorname{GM}(1, n)$ model can describe the relationship between the variables, but generally not used for prediction.

To establish the GM $(1,1)$ gray model for all indicators in TECR:

$$
\frac{d x^{(l)}{ }_{i}}{d t}+a_{i} x_{i}^{(I)}=u_{i}
$$

Solving based on the least squares method:

$$
B_{i}=\left[\begin{array}{cc}
-\frac{1}{2}\left(x_{i}^{(l)}(1)+x_{i}^{(l)}(2)\right) & 1 \\
-\frac{1}{2}\left(x_{i}^{(l)}(2)+x_{i}^{(l)}(3)\right) & 1 \\
\vdots & \vdots \\
-\frac{1}{2}\left(x_{i}^{(l)}(k-1)+x_{i}^{(l)}(k)\right) & 1
\end{array}\right]
$$

$$
\begin{gathered}
Y_{i}=\left[x_{i}^{(0)}(2), x_{i}^{(0)}(3), \cdots, x_{i}^{(0)}(k)\right]^{T} \\
x_{i}^{(1)}(k)=\sum_{m=1}^{k} x_{i}^{(0)}(m)
\end{gathered}
$$

Early warning indicators $x_{i}^{(0)}(i=1,2, \cdots, n)$ may constitute the $\mathrm{n}$ multi-differential equations, transform into the standard form, we can obtain the state equation of system forecast model, the ultimate predictive result is

$$
\begin{aligned}
& x_{i}^{(I)}(k+1)=\left[x_{i}^{(0)}(l)-\frac{u_{i}}{a_{i}}\right] e^{-a_{i} k}+\frac{u_{i}}{a_{i}} \\
& x_{i}^{(0)}(k+1)=x_{i}^{(l)}(k+1)-x_{i}^{(I)}(k)
\end{aligned}
$$

\section{EMPIRICAL RESEARCH}

Monitoring levels $\mathrm{Y}$ of the Nandaihe international entertainment center. TECR are divided into four intervals, namely $\mathrm{Y}=\left\{\mathrm{Y}_{1}, \mathrm{Y}_{2}, \mathrm{Y}_{3}, \mathrm{Y}_{4}\right\}, \mathrm{Y}_{1}$ is $[0,0.4)$ which is corresponded to "weak-load conditions", $Y_{2}$ is[0.4,0.7) which is corresponded to "normal conditions", $\mathrm{Y}_{3}$ is $[0.7,0.9)$ which is corresponded to "low degree overload", $\mathrm{Y}_{4}$ is $(0.9,1]$ which is corresponded to "high degree overload". The data in Table 3 of the 2006 to 2011 is used to grey predict by fuzzy reasoning method which the result is 0.7131 in 2012 July, concludes that the TECC is in a low overload state [6]

In order to a better comparative study where the utilization of TECC is generated by the fuzzy inference method. The fuzzy evaluation method mentioned in is adopted to calculate the utilization of TECC. Develop 60 questionnaires for the scenic in July 2012, the investigation objects include: 20 scenic spots managers, the selection of managers related to the area within multiple management; 20 person which is familiar with the Qinhuangdao tourism development, including the leadership of Qinhuangdao Tourism Municipal Bureau(2 people), the leadership of Qinhuangdao City in the infrastructure sector(2 people), the personnel of tourism-related enterprises (such as: hotels, travel agencies, shopping and entertainment, etc.) (10 people), university experts (6 people), tourists in the Nandaihe international entertainment center scenic spots $(20$ people). Finally obtain the warning state of tourism environment carrying capacity utilization in July is 0.7082 which is very close to 0.7131 by fuzzy reasoning method. The result illustrates the early-warning model designed is feasible and effective.

\section{CONCLUSION}

Early-warning system of tourism environment carrying capacity is a highly complex nonlinear system and it is very difficult to establish a precise mathematical model. In this 
paper, the fuzzy reasoning method and grey forecasting is adopted to deal with this system. Fuzzy inference method is used to early-warning of Nandaihe International entertainment center based on the proposed evaluation index of tourism environment carrying capacity system. Nandaihe international amusement centre spot as an example proves that the early-warning model designed is feasible and effective [7].

\section{ACKNOWLEDGMENT}

This article is funded by the general project of the Ministry of Education, Humanities and Social Sciences (Western and Frontier Areas Projects) (11XJC630016), The Youth Foundation of National (10CGL046), Gansu Province Natural Science Fund Project (1112RJZA010) and Training Program at the Lanzhou University of Technology HongLiu Young Teachers (Q201213) and (Q201210).

TABLE III. STATISTICS AND FORECAST DATA OF TOURISM ENVIRONMENT CARRYING CAPACITY IN NANDAIHE INTERNATIONAL AMUSEMENT CENTRE

\begin{tabular}{|c|c|c|c|c|c|c|c|c|c|c|c|c|c|}
\hline July & & & & & & & & & & & & & \\
\hline & $\mathbf{x}_{1}$ & $\mathbf{x}_{2}$ & $\mathbf{x}_{3}$ & $\mathbf{x}_{4}$ & $\mathbf{x}_{5}$ & $\mathbf{x}_{6}$ & $\mathbf{x}_{7}$ & $\mathbf{X}_{8}$ & $\mathbf{X}_{9}$ & $\mathbf{x}_{10}$ & $\mathbf{x}_{11}$ & $\mathbf{x}_{12}$ & $\mathbf{x}_{13}$ \\
\hline 2006 & 0.461 & 0.585 & 0.311 & 0.341 & 0.336 & 0.617 & 0.524 & 0.459 & 0.429 & 0.569 & 0.548 & 0.228 & 0.669 \\
\hline 2007 & 0.552 & 0.651 & 0.345 & 0.318 & 0.425 & 0.531 & 0.553 & 0.568 & 0.557 & 0.614 & 0.586 & 0.326 & 0.656 \\
\hline 2008 & 0.613 & 0.703 & 0.477 & 0.397 & 0.513 & 0.565 & 0.695 & 0.547 & 0.595 & 0.632 & 0.637 & 0.374 & 0.717 \\
\hline 2009 & 0.627 & 0.667 & 0.452 & 0.453 & 0.588 & 0.734 & 0.672 & 0.634 & 0.667 & 0.656 & 0.723 & 0.447 & 0.753 \\
\hline 2010 & 0.631 & 0.728 & 0.563 & 0.644 & 0.619 & 0.671 & 0.767 & 0.716 & 0.724 & 0.634 & 0.658 & 0.582 & 0.744 \\
\hline 2011 & 0.655 & 0.726 & 0.647 & 0.595 & 0.632 & 0.788 & 0.735 & 0.803 & 0.733 & 0.658 & 0.714 & 0.563 & 0.802 \\
\hline $\begin{array}{l}\text { The predictive value in } \\
\qquad 2012\end{array}$ & 0.671 & 0.731 & 0.611 & 0.574 & 0.648 & 0.813 & 0.751 & 0.812 & 0.741 & 0.662 & 0.723 & 0.572 & 0.811 \\
\hline $\begin{array}{l}\text { The actual value in } \\
\qquad 2012\end{array}$ & 0.688 & 0.681 & 0.572 & 0.612 & 0.659 & 0.832 & 0.783 & 0.798 & 0.732 & 0.658 & 0.689 & 0.501 & 0.788 \\
\hline $\begin{array}{l}\text { The predictive value in } \\
\qquad 2013\end{array}$ & 0.694 & 0.703 & 0.653 & 0.631 & 0.653 & 0.854 & 0.812 & 0.829 & 0.748 & 0.666 & 0.728 & 0.605 & 0.827 \\
\hline
\end{tabular}

\section{REFERENCES}

[1] Liu Jia,Liu Ning,Yang Kun. A Review of Tourism Environment Carrying Capacity Warning [J]. Journal of Ocean University of China (Social Sciences), 2012, 1:73-77.

[2] Yang Xiuping,Weng Gangmin. Research of Early-warning System about Tourism Sustainable Development Based on Chaotic BP Neural Network [J]. Future and Development, 2011, 4: 25-28.

[3] Weng Gangmin. Dynamic Evaluation of Tourism Environment Carrying Capacity and its Management [D]. Doctoral Dissertation of Tianjin University, December 2006.
[4] Weng Gangmin, Zhao Liming,Yang Xiuping. Research on Forewarning System for Carrying Capacity in Scenic Spots [J]. Journal of China University of Geosciences (Social Sciences Edition), 2005, 5(4):55-59.

[5] Xiao Weiyue. A Study on the Uncertainty Inference in Fuzzy Rule [J]. Journal of Applied Sciences, 2001, 20 (1):94-98..

[6] Li Erchao. The Study of Robot Force Control Based on Uncertain Environment [D]. Lanzhou University of Technology, December 2011.

[7] Yang Xiuping,Weng Gangmin. Tourism Environment Carrying Capacity Study Based on Fuzzy Evaluation [J]. Commercial Times, 2007, 25:85-86. 